Article

\title{
RpoN Regulates Virulence Factors of Pseudomonas aeruginosa via Modulating the PqsR Quorum Sensing Regulator
}

\author{
Zhao Cai ${ }^{1,2,+}$, Yang Liu ${ }^{1,+}$, Yicai Chen ${ }^{1}$, Joey Kuok Hoong Yam ${ }^{1,2}$, Su Chuen Chew ${ }^{1,2}$, \\ Song Lin Chua ${ }^{1}$, Ke Wang ${ }^{3}$, Michael Givskov ${ }^{1,4}$ and Liang Yang ${ }^{1,5, *}$ \\ Received: 13 August 2015; Accepted: 23 November 2015; Published: 30 November 2015 \\ Academic Editor: Nicholas Delihas \\ 1 Singapore Centre for Environmental Life Sciences Engineering (SCELSE), Nanyang Technological \\ University, Singapore 637551; caiz0013@e.ntu.edu.sg (Z.C.); liu_yang@ntu.edu.sg (Y.L.); \\ chenyc@ntu.edu.sg (Y.C.); yamk0002@e.ntu.edu.sg (J.K.H.Y.); schew005@e.ntu.edu.sg (S.C.C.); \\ chuasonglin@nus.edu.sg (S.L.C.); mgivskov@sund.ku.dk (M.G.) \\ 2 Interdisciplinary Graduate School, Nanyang Technological University, Singapore 637551 \\ 3 Department of Respiratory Disease, First Affiliated Hospital of Guangxi Medical University, \\ Nanning 530000, China; keewang@hotmail.com \\ 4 Costerton Biofilm Center, Department of International Health, Immunology and Microbiology, \\ University of Copenhagen, 2200 København N, Denmark \\ 5 School of Biological Sciences, Nanyang Technological University, Singapore 637551 \\ * Correspondence: yangliang@ntu.edu.sg; Tel.: +65-6592-3085; Fax: +65-6515-6751 \\ + These authors contributed equally to this work.
}

\begin{abstract}
The alternative sigma factor RpoN regulates many cell functions, such as motility, quorum sensing, and virulence in the opportunistic pathogen Pseudomonas aeruginosa (P. aeruginosa). $P$. aeruginosa often evolves rpoN-negative variants during the chronic infection in cystic fibrosis patients. It is unclear how RpoN interacts with other regulatory mechanisms to control virulence of P. aeruginosa. In this study, we show that RpoN modulates the function of PqsR, a quorum sensing receptor regulating production of virulence factors including the phenazine pyocyanin. The $\Delta r p o N$ mutant is able to synthesize 4-quinolone signal molecule HHQ but unable to activate PqsR and Pseudomonas quinolone signal ( $p q s)$ quorum sensing. The $\Delta r p o N$ mutant produces minimal level of pyocyanin and is unable to produce the anti-staphylococcal agents. Providing pqsR in trans in the $\triangle r p o N$ mutant restores its $p q s$ quorum sensing and virulence factor production to the wild-type level. Our study provides evidence that RpoN has a regulatory effect on P. aeruginosa virulence through modulating the function of the PqsR quorum sensing regulator.
\end{abstract}

Keywords: Pseudomonas aeruginosa; rpoN; pqsR; quorum sensing

\section{Introduction}

Bacterial chronic infections raise a huge burden for public health today, which significantly prolong hospitalization period and increase treatment costs. It is well known that bacteria are able to adapt their genome and physiology during chronic infections [1-3]. For example, the opportunistic pathogen Pseudomonas aeruginosa (P. aeruginosa) is able to colonize in the airway of cystic fibrosis (CF) patient for decades [2]. Colonization in CF patients has a high frequency to select for mutations in las $R, p v d S, m u c A$, and rpoN genes of the P. aeruginosa genome [4,5]. Understanding how these genetic adaptations affect the bacterial physiology and the microbial ecology is essential for development of strategies for infection control. 
One major feature of $P$. aeruginosa $\mathrm{CF}$ adaptation is the reduction of virulence. P. aeruginosa employs the cell-to-cell communication (quorum sensing) to regulate expression of a large set of virulence genes such as genes required for the synthesis of pyocyanin, elastase, proteases and iron siderophore pyoverdine [6,7]. Mutations in lasR and podS of CF isolates abolish the las quorum sensing and siderophore synthesis, respectively, and thus reduce P. aeruginosa virulence $[4,5]$. Mutations in mucA and rpoN genes of $\mathrm{CF}$ isolates are believed to be more important for the adaptive response of $P$. aeruginosa towards the host immune systems. The mucA mutation of CF P. aeruginosa isolates leads to conversion from non-mucoid to mucoid phenotype, characterized by an over production of the alginate polysaccharide [8]. Large amounts of alginate produced by the mucA mutants provide protection to the bacterial cells against the phagocytic cells [9]. The rpoN mutation of CF P. aeruginosa isolates leads to deficiency in surface pilus, flagellum synthesis and their mediated motilities [10], which confers the immune evasion capacity of the P. aeruginosa [11,12].

The rpoN mutation has a profound impact on P. aeruginosa by affecting metabolism, motility, biofilm formation and quorum sensing [4,13]. It is unclear how RpoN regulates quorum sensing genes in P. aeruginosa and whether this is going to affect the microbial ecology of CF lungs. Here, we showed that RpoN modulates the functions of the quorum sensing receptor PqsR, which determines the Pseudomonas quinolone signal (pqs) quorum sensing-regulated virulence factors and biofilm formation.

\section{Results}

\subsection{RpoN Regulates P. aeruginosa pqs Quorum Sensing via PqsR}

The $\Delta r p o N$ mutant is well known to be deficient in pyocyanin production, which is under direct control by the Pseudomonas quinolone signal (pqs)-mediated quorum sensing mechanism [14]. In the $p q s$ quorum sensing system, auto-induction of the $p q s A B C D E$ operon is driven by the PqsR, which is known to bind to the $p q s A$ promoter and induce its transcription in the presence of the 2-heptyl-3-hydroxy-4(1H)-quinolone (PQS) or 4-hydroxy-2-heptylquinoline (HHQ) [14]. To elucidate the regulatory role of RpoN on the pqs quorum sensing mechanism, we monitored the expression of the $p q s A$ promoter-gfp fusion $\mathrm{p}_{p q s} A^{-} g f p$ in wild-type PAO1, $\triangle r p o N$ mutant and the $\triangle r p o N C O M$ complementary strain. We observed that the expression level of the $p_{p q s}$ - $g f p$ fusion in the $\triangle r p o N$ mutant is significantly lower compared to that in the wild-type PAO1 and the $\triangle r p o N C O M$ complementary strain (Figure 1A). HPLC analysis showed that the $\triangle r p o N$ mutant produced similar level of HHQ compared to the PAO1 (Figure 1B), confirming that the $p q s A B C D E$ operon is functional in the $\triangle r p o N$ mutant.

Furthermore, we found that addition of synthesized PQS to the $\triangle r p o N$ mutant was unable to affect the expression of the $\mathrm{p}_{p q s}$ - $g f p$ fusion in the $\Delta r p o N$ mutant (Figure 1A), which indicates that there might be no functional PqsR in the $\triangle r p o N$ mutant. We thus evaluated the effect of over-expressing $p q s R$ on the $p q s$ signaling of the $\Delta r p o N$ mutant. Overexpressing $p q s R$ under the lac promoter in a pME6032-pqsR vector in the $\Delta r p o N$ mutant restored its pqs signaling (Figure 1A). We also investigated the regulation of RpoN on $p q s$ signaling using P. aeruginosa strains from another background mPAO1 and obtained similar results (Figure S1).

\subsection{RpoN Regulates Virulence Factors and Interspecies Competition through pqs Signaling}

The $p q s$ quorum sensing regulates expression of virulence genes (e.g., pyocyanin biosynthesis genes) and mediates interspecies interactions and biofilm formation [15-18]. We then further examined whether RpoN affects these phenotypes in a pqs-dependent manner. Pyocyanin quantification assay showed that the $\triangle r p o N$ mutant produced much less pyocyanin compared to the wild-type PAO1 (Figure 2A). The deficiency in pyocyanin production of the $\Delta r p o N$ mutant was restored by both $r p o N$ complementation and $p q s R$ overexpression (Figure 2A). The control vector pME6032 has negligible effect on the pyocyanin production of the $\Delta r p o N$ mutant (Figure 2A). 

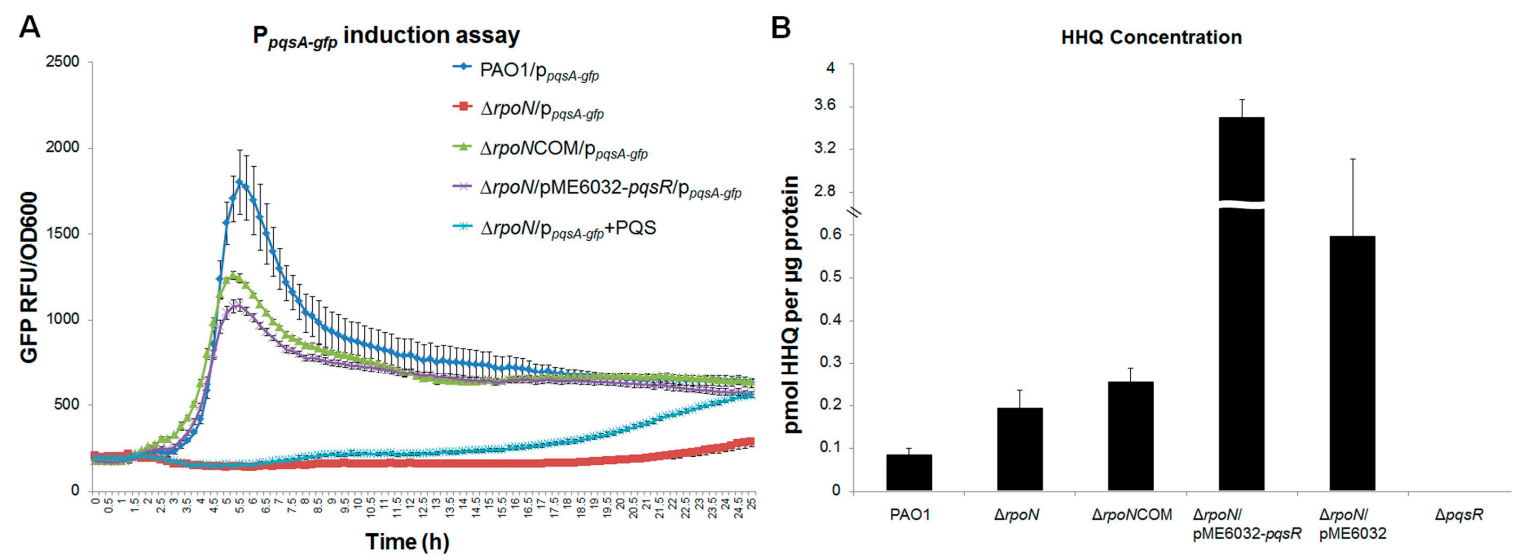

Figure 1. Regulation of $p q s$ quorum sensing by RpoN. (A) Induction of $\mathrm{p}_{p q s A-g f p}$ transcriptional fusion in PAO1 wild-type, $\Delta r p o N, \Delta r p o N C O M, \Delta r p o N / p M E 6032-p q s R$ and $\Delta r p o N$ + PQS (2-heptyl-3-hydroxy-4(1H)-quinolone). Cultures were monitored for their gfp fluorescent protein (GFP) fluorescence by using a Magellen Tecan ${ }^{\circledR}$ Infinite 200 PRO microplate reader. Means and standard deviations (S.D.) in relative fluorescence units (RFU) from triplicate experiments are shown; (B) High-performance liquid chromatography (HPLC) analysis of HHQ (4-hydroxy-2-heptylquinoline) production by PAO1, $\Delta r p o N, \Delta r p o N C O M, \Delta r p o N / p M E 6032-p q s R$, $\Delta r p o N / p M E 6032$ and $\Delta p q s R$. Means and S.D. from triplicate experiments are shown.

A

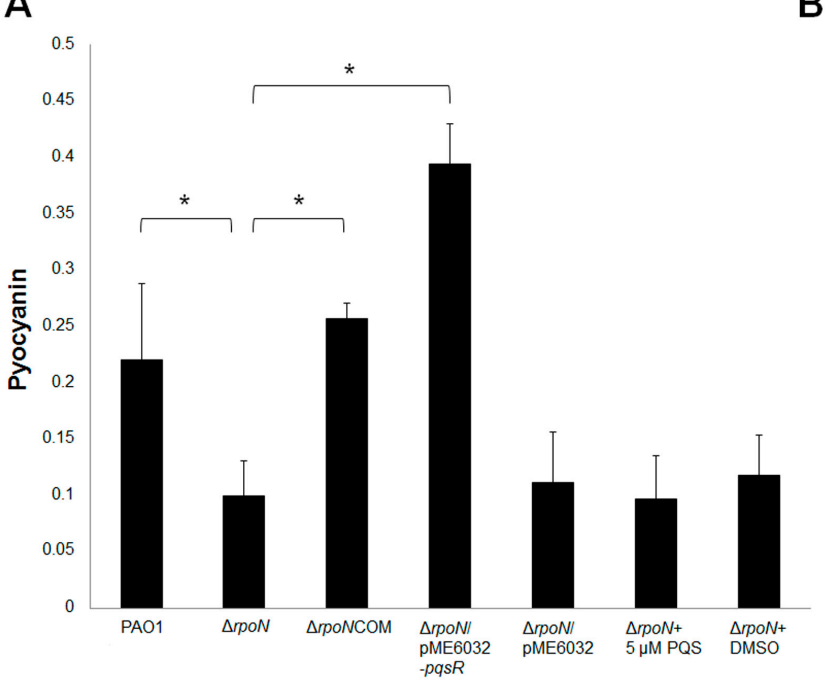

B
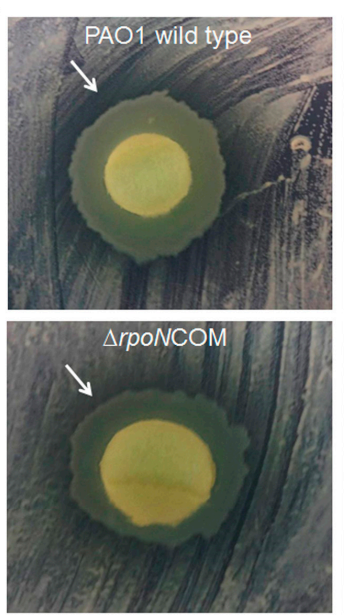

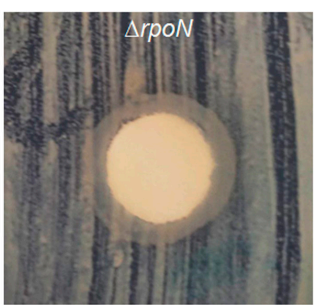

$\Delta r p o N / p M E 6032-p q s R$

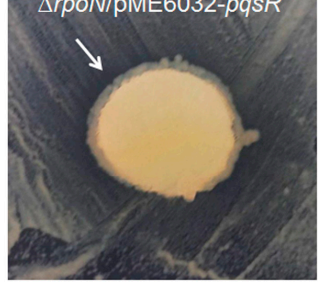

Figure 2. (A) Pyocyanin produced by PAO1 wild-type, $\Delta r p o N, \Delta r p o N C O M, \Delta r p o N / p M E 6032-p q s R$ and $\Delta r p o N / p M E 6032$ was determined by the chloroform extraction method. Means and S.D. from triplicate experiments are shown. Pyocyanin absorbance at $\mathrm{OD}_{520} \mathrm{~nm}$ was normalized by culture cell density $\mathrm{OD}_{600 \mathrm{~nm}}$. Student's $t$-test was performed for testing differences between groups. ${ }^{*} p \leqslant 0.05$; (B) Inhibition of the growth of Staphylococcus aureus 15981 by (i) PAO1; (ii) $\Delta r p o N$; (iii) $\Delta r p o N C O M$; and (iv) $\Delta r p o N / p M E 6032-p q s R$ on LB agar plates. White arrows indicate the inhibitory zones of growth.

Interspecies interactions play an important role during the progression of diseases, as most of the infections are polymicroibal in nature. P. aeruginosa coexists with many other microbial species during CF infections. One of the other dominant species in the CF airway is Staphylococcus aureus (S. aureus). $P$. aeruginosa was shown to inhibit Staphylococcus growth via the $p q s$ quorum sensing-dependent mechanism $[19,20]$. We examined the impact of $r p o N$ mutation on interactions between P. aeruginosa and S. aureus. We found that unlike the wild-type PAO1, the $\triangle r p o N$ mutant could not inhibit the growth of S. aureus in the plate growth assay (Figure 2B). The $\triangle r p o N C O M$ complementation strain 
and the $p q s R$ overexpressing $\Delta r p o N / p M E 6032-p q s R$ strain restored the capacity of the $\Delta r p o N$ mutant to inhibit the growth of $S$. aureus on LB agar plates (Figure 2B). We also examined the impact of rpoN mutation on interactions between $P$. aeruginosa and S. aureus in biofilm co-cultures. Similarly, we found that the $\triangle r p o N$ mutant gained less fitness against $S$. aureus in biofilm co-cultures compared to the PAO1 strain (Figure $3 \mathrm{~A}, \mathrm{~B}$ ). The $\triangle r p o N C O M$ complementation strain had similar fitness to the PAO1 wild-type against the $S$. aureus in biofilm co-cultures. However, $p q s R$ overexpression in the $\triangle r p o N$ mutant only partially restored its fitness against $S$. aureus in biofilm co-cultures (Figure 3A,B). This suggests that other factors regulated by RpoN but not by PqsR might play a role in competition between $P$. aeruginosa and S. aureus in biofilm co-cultures.

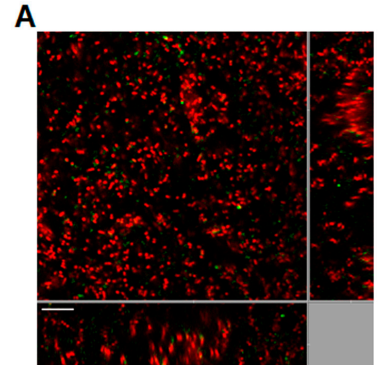

PAO1 vs S. aureus



$\Delta r p o N C O M$ vs S. aureus

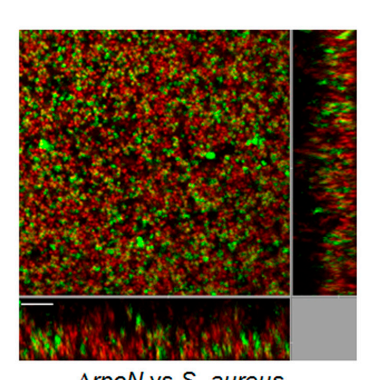

$\Delta r p o N$ vs $S$. aureus

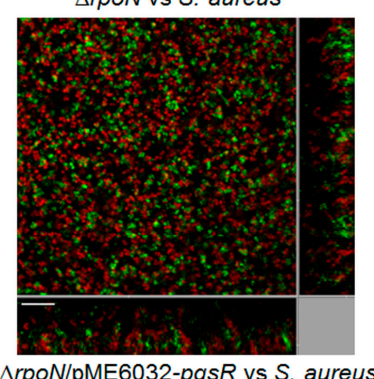

B

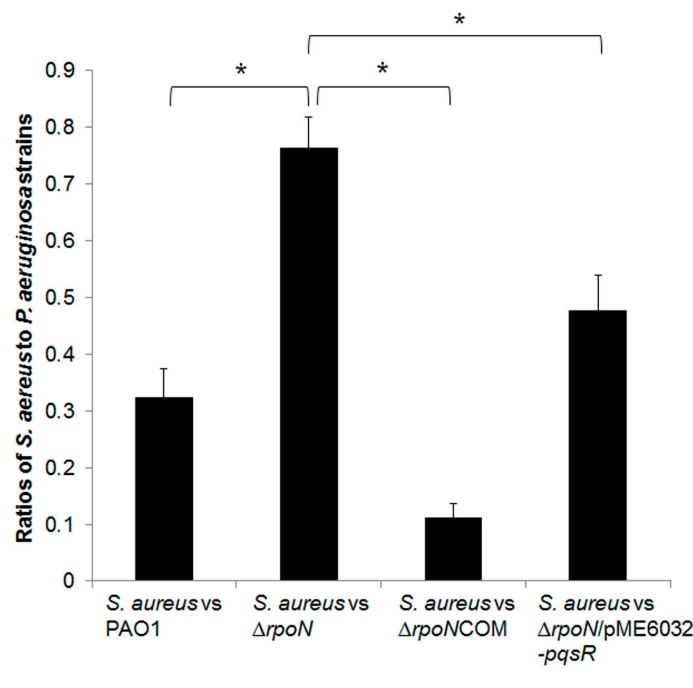

Figure 3. (A) Images of biofilm co-cultures of S. aureus 15981/pSB2019 with (i) PAO1; (ii) $\Delta r p o N$; (iii) $\Delta r p o N C O M$ and (iv) $\Delta r p o N / p M E 6032-p q s R$, respectively. S. aureus 15981/pSB2019 appeared green due to GFP expression whereas $P$. aeruginosa strains were stained with red fluorescent dye CYTO62 used to generate the simulated 3D images (Bitplane, AG). Scale bar, $20 \mu \mathrm{m}$; (B) Biomass ratios of $S$. aureus to $P$. aeruginosa strains from different biofilm co-cultures were calculated using Imaris and shown in the histogram. Means and S.D. from triplicate experiments are shown. Student's $t$-test was performed for testing differences between groups. ${ }^{*} p \leqslant 0.05$.

\subsection{RpoN Mediates Killing of Caenorhabditis elegans through pqs Quorum Sensing}

P. aeruginosa is able to kill Caenorhabditis elegans (C. elegans) using RpoN-regulated virulence products [21], we further examined whether pqs quorum sensing is involved in the RpoN-mediated killing of $C$. elegans by P. aeruginosa. As we expected, the death rate of C. elegans was much lower in the $\Delta r p o N$ mutant compared to the wild-type PAO1 strain (Figure 4). $\Delta r p o N$ mutants complemented with plasmids carrying either $r p o N$ gene or pqsR gene restored its virulence against $C$. elegans (Figure 4). The death rate of $C$. elegans caused by $\Delta r p o N C O M$ and $\Delta r p o N / p M E 6032-p q s R$ strains was similar but slightly lower than that of the wild-type PAO1 strain. The $\triangle r p o N$ mutant carrying pME6032 control vector expressed basal level of virulence only. These results are in accordance with the results we observed from pyocyanin quantification and $\mathrm{p}_{p q s} A_{-} g f p$ induction assay, suggesting that RpoN regulates virulence through PqsR. 


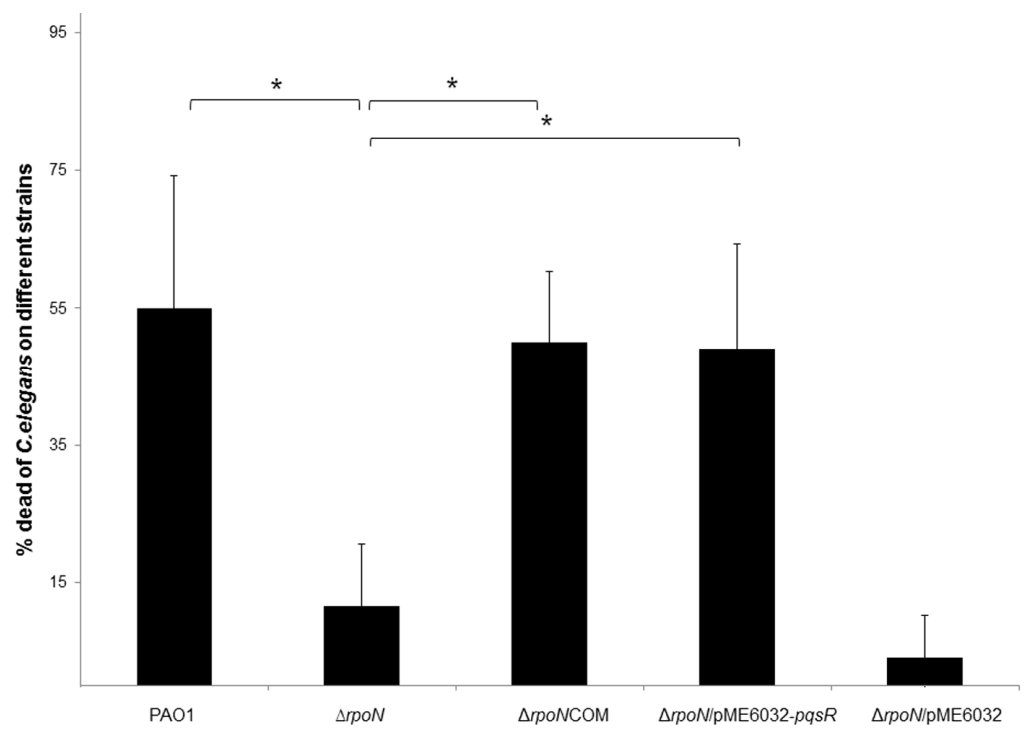

Figure 4. Death rates of Caenorhabditis elegans (C. elegans) growing on the lawn of different P. aeruginosa strains on agar plates. Means and S.D. from six replicates are shown. One-way ANOVA was performed for testing differences between groups. ${ }^{*} p \leqslant 0.05$.

\subsection{Discussion}

RpoN ( $\sigma 54)$ is a conserved regulator in the bacterial kingdom that plays essential roles in regulating metabolism, motility and virulence of different species [22,23]. $\Delta r p o N$ mutants are selected during chronic adaptation of $P$. aeruginosa in the CF airways [4]. One of the reasons for this evolutionary trait is that the $\triangle r p o N$ mutant is able to escape the phagocytosis because of its deficiency in motility [10,12]. Another reason that $r p o N$ mutation might be selected is due to the fact that the $\triangle r p o N$ mutant downregulates its virulence, which is also an important adaptation strategy for chronic $\mathrm{CF}$ infections [24,25]. It is unclear how RpoN regulates virulence in P. aeruginosa.

In the present study, we demonstrated that RpoN is able to regulate virulence factors via modulating the $p q s$ quorum sensing. Specifically, our results suggest that PqsR is controlled by RpoN, which is in accordance with a recent study showing that RpoN binds with the $p q s R$ sequence via ChIP-seq analysis [26].

Recent evidence suggested that nutrient clues could modulate pqs quorum sensing post-transcriptionally through the PqsR. For example, under oxygen limiting condition, the transcriptional regulator Anr is able to activate expression of the small non-coding RNA PhrS, which further stimulates translation of $p q s R$ and activate $p q s$ quorum sensing [27]. The small non-coding RNA CrcZ, which is required for sequester of the RNA-binding catabolite repression control protein $\mathrm{Crc}$ and Hfq in Pseudomonas, was also shown by us and others to negatively control pqs quorum sensing [18]. Hfq was shown to be able to bind to and stabilize the small non-coding RNA RsmY, which leads to abrogate of the RsmA, a global RNA-binding posttranscriptional regulator that can repress quorum sensing in P. aeruginosa [28]. Further studies should be carried out to investigate the roles of PhrS and $\mathrm{CrcZ}$ in mediating the regulation of RpoN on pqs quorum sensing in P. aeruginosa as well as in other species.

\section{Experimental Section}

\subsection{Bacterial Strains, Plasmids, and Growth Conditions}

Bacterial strains and plasmid vectors used in this study are listed in Table 1. 
Table 1. Bacterial strains, plasmids and primers used in this study.

\begin{tabular}{|c|c|c|}
\hline Strain(s) or Plasmid & Relevant Characteristic(s) & $\begin{array}{l}\text { Source or } \\
\text { Reference }\end{array}$ \\
\hline \multicolumn{3}{|c|}{ P. aeruginosa strains } \\
\hline PAO1 & Prototypic wild-type strain & [13] \\
\hline$\Delta r p o N$ & $\mathrm{Gm}^{\mathrm{r}} ;$ rpoN derivative of PAO1 constructed by allelic exchange & [13] \\
\hline$\triangle r p o N C O M$ & $\mathrm{Gm}^{\mathrm{r}} ; \mathrm{Tc}^{\mathrm{r}} ; \Delta r p o N$ carrying the $\mathrm{pME} 6031-r p o N$ vector & This work \\
\hline$\Delta r p o N / p M E 6032-p q s R$ & $\mathrm{Gm}^{\mathrm{r}} ; \mathrm{Tc}^{\mathrm{r}} ; \Delta r p o N$ carrying the $\mathrm{pME} 6032-p q s R$ vector & This work \\
\hline$\Delta r p o N / p M E 6032-p q s R / p_{p q s} A-g f p$ & $\mathrm{Gm}^{\mathrm{r}} ; \mathrm{Tc}^{\mathrm{r}} ; \mathrm{Carb}^{\mathrm{r}} ; \Delta r p o N / \mathrm{pME} 6032-p q s R$ carrying the $\mathrm{p}_{p q s A-g f p \text { vector }}$ & This work \\
\hline$\Delta r p o N C O M / p_{p q s} A-g f p$ & $\mathrm{Gm}^{\mathrm{r}} ; \mathrm{Tc}^{\mathrm{r}} ; \mathrm{Carb}^{\mathrm{r}} ; \Delta r p o N C O M$ carrying the $\mathrm{p}_{p q s} A-g f p$ vector & This work \\
\hline$\Delta r p o N / p M E 6032$ & $\mathrm{Gm}^{\mathrm{r}} ; \mathrm{Tc}^{\mathrm{r}} ; \Delta r p o N$ carrying the pME6032 vector & This work \\
\hline$\Delta p q s R$ & $p q s R$ derivative of PAO1 constructed by allelic exchange & [15] \\
\hline \multicolumn{3}{|c|}{ Staphylococcus aureus } \\
\hline 15981 & Prototypic wild-type strain & [29] \\
\hline $15981 / \mathrm{pSB} 2019$ & $\mathrm{Chl}^{\mathrm{r}} ; 15981$ carrying the pSB2019 gfp-expressing vector & [29] \\
\hline \multicolumn{3}{|c|}{ Plasmids } \\
\hline pME6031 & $\mathrm{Tc}^{\mathrm{r}}$; Broad-host-range cloning vector & [30] \\
\hline pME6031-rpoN & $\mathrm{Tc}^{\mathrm{r}}$; pME6031 carrying the rpoN gene & [4] \\
\hline pME6032 & $\mathrm{Tc}^{\mathrm{r}}$; broad host range vector & [30] \\
\hline pME6032-pqsR & $\mathrm{Tc}^{\mathrm{r}} ;$ pME6032 carrying the $p q s R$ gene & [15] \\
\hline $\mathrm{p}_{p q s A-g f p}$ & $\mathrm{Gm}^{\mathrm{r}} ; \mathrm{Carb}^{\mathrm{r}} ; \mathrm{pUCP} 22$ carrying the $p q s A-g f p$ transcriptional fusion & [16] \\
\hline
\end{tabular}

The Escherichia coli (E. coli) DH5a lab strain was used for standard DNA manipulations and plasmid maintenance. LB medium [31] was used for cultivation of E. coli strains. P. aeruginosa strains were cultivated in ABT minimal medium [32] supplemented with 2 g glucose $\mathrm{L}^{-1}$ and $2 \mathrm{~g}$ casamino acids $\mathrm{L}^{-1}$ (ABTGC) at $37^{\circ} \mathrm{C}$. King's medium A (Sigma-Aldrich, Singapore) was used for the P. aeruginosa cultivation for the pyocyanin assay. Batch cultivation of $S$. aureus was carried out at $37{ }^{\circ} \mathrm{C}$ in Tryptic Soy Broth (TSB) medium (BD Biosciences, Singapore). The LB medium was supplemented with $100 \mu \mathrm{g}$ ampicillin $(\mathrm{Ap}) \cdot \mathrm{mL}^{-1}, 15 \mu \mathrm{g}$ gentamicin $(\mathrm{Gm}) \cdot \mathrm{mL}^{-1}, 15 \mu \mathrm{g}$ tetracycline (Tc) $\cdot \mathrm{mL}^{-1}, 8 \mu \mathrm{g}$ chloramphenicol $(\mathrm{Cm}) \cdot \mathrm{mL}^{-1}$ for plasmid maintenance in $E$. coli when necessary. The TSB medium was supplemented with $10 \mu \mathrm{g}$ chloramphenicol $(\mathrm{Cm}) \cdot \mathrm{mL}^{-1}$ for plasmid maintenance in S. aureus. The ABTGC medium was supplemented with $30 \mu \mathrm{g} \mathrm{Gm} \cdot \mathrm{mL}^{-1}, 50 \mu \mathrm{g} \mathrm{Tc} \cdot \mathrm{mL}^{-1}, 200 \mu \mathrm{g}$ carbenicillin $(\mathrm{Cb}) \cdot \mathrm{mL}^{-1}$ for marker selection in P. aeruginosa when necessary.

\subsection{HHQ Quantification by High Performance Liquid Chromatography (HPLC)}

P. aeruginosa strains were grown in triplicates in $25 \mathrm{~mL}$ of ABTGC medium at $37^{\circ} \mathrm{C}, 200 \mathrm{rpm}$ for $8 \mathrm{~h}$ until entering early stationary phase. Cultures were centrifuged $(10,000 \times \mathrm{g}, 10 \mathrm{~min})$ and $20 \mathrm{~mL}$ of supernatants were filtered through the $0.22 \mu \mathrm{m}$ Hydrophilic Cartridge Filters (Millipore, Singapore). HHQ was extracted by $10 \mathrm{~mL}$ of acidified ethyl acetate for three times. The ethyl actate fraction was dried and the residue was re-suspended in $200 \mu \mathrm{L}$ of isopropal alcohol as previously described [33]. The concentration of HHQ was measured by High Performance Liquid Chromatography (HPLC). The reverse-phase $C_{18}$ Targa column $(4.6 \mathrm{~mm} \times 150 \mathrm{~mm}, 5 \mu \mathrm{m})$ (catalog number: TS-1546-C185) was used with solvent $A(10 \mathrm{mM}$ ammonium acetate in water) and solvent $B(10 \mathrm{mM}$ ammonium acetate in methanol) at a flow rate of $0.3 \mathrm{~mL} \cdot \mathrm{min}^{-1}$. The injection volume was $20 \mu \mathrm{L}$ and $314 \mathrm{~nm}$ was used as the detection wavelength. The eluent gradient was as follows: $0 \mathrm{~min}, 30 \% \mathrm{~B}, 0$ to $3 \mathrm{~min}, 70 \% \mathrm{~B}$; 3 to $29 \mathrm{~min}, 100 \% \mathrm{~B} ; 29$ to $36 \mathrm{~min}, 100 \% \mathrm{~B} ; 36$ to $40 \mathrm{~min}, 20 \% \mathrm{~B} ; 40$ to $42 \mathrm{~min}, 20 \%$ B. The retention time of HHQ was at $22.5 \mathrm{~min}$. HHQ concentrations obtained by HPLC analysis were normalized by protein concentration.

\subsection{Pyocyanin Quantification}

Bacterial cultures were grown in $10 \mathrm{~mL}$ of King's medium A for $24 \mathrm{~h}$ at $37^{\circ} \mathrm{C}, 200 \mathrm{rpm}$. Cell-free supernatants were collected by centrifugation and filtered through the $0.22 \mu \mathrm{m}$ Hydrophilic Cartridge Filters (Millipore, Singapore). $5 \mathrm{~mL}$ of cell-free supernatants and medium control were transferred to new tubes where $1 \mathrm{~mL}$ of chloroform were added and mixed. The layer of chloroform at bottom was 
transferred to new tubes after settling. Pyocyanin was extracted from chloroform using $200 \mu \mathrm{L}$ of $0.2 \mathrm{M} \mathrm{HCl}$ by vigorous mixing. The quantity of pyocyanin was measured by absorbance at $\mathrm{OD}_{520 \mathrm{~nm}}$. Pyocyanin quantities were normalized against the $\mathrm{OD}_{600 \mathrm{~nm}}$ values of the cultures.

\subsection{Mixed-Species Biofilm Assay}

Mixed species biofilms were established by co-culturing S. aureus 15981/pSB2019 and P. aeruginosa PAO1 wild-type, $\Delta r p o N, \Delta r p o N C O M$, and $\Delta r p o N / p M E 6032-p q s R$ mutant, respectively, as previously described [34]. S. aureus 15981/pSB2019 appeared green due to gfp expression whereas $P$. aeruginosa strains were stained with red fluorescent dye, SYTO62. Imaging of biofilms was done using a Zeiss LSM780 CLSM with a $63 \times / 1.4$ objective. Imaris software package (Bitplane AG, Zürich, Switzerland) was used to generate the simulated 3D images and calculation of the biovolumes of biofilms.

\subsection{Staphylococcus aureus Inhibitory Assay}

S. aureus overnight cultures were washed with PBS for three times and diluted to $\mathrm{OD}_{600 \mathrm{~nm}}=0.1 .100 \mu \mathrm{L}$ of diluted cultures were plated evenly onto LB agar plates and spread-dried. Filter paper discs were placed onto the surface of LB agar plates on top of the $S$. aureus lawn. P. aeruginosa PAO1 wild-type, $\Delta r p o N, \Delta r p o N C O M$, and $\Delta r p o N / p M E 6032-p q s R$ overnight cultures were washed and diluted to $\mathrm{OD}_{600 \mathrm{~nm}}=0.1 .20 \mu \mathrm{L}$ of diluted P. aeruginosa cultures were taken and dripped onto filter paper discs. Agar plates were then incubated at $37^{\circ} \mathrm{C}$ for overnight. S. aureus inhibitory effect was determined by the sizes of inhibiting zones.

\section{6. $P_{p q s A^{-}} g f p$ Induction Assay}

$\mathrm{PAO} 1 / \mathrm{p}_{p q s} A-g f p, \quad \Delta r p o N / \mathrm{p}_{p q s} A-g f p, \quad \Delta r p o N C O M / \mathrm{p}_{p q s A-g f p,}$ and $\Delta r p o N / \mathrm{pME6032-pqsR/}$ $\mathrm{p}_{p q s} A-g f p$ strains were cultivated overnight in LB broth in the presence of respective antibiotics. Overnight cultures of these strains were diluted in ABTGC medium to $\mathrm{OD}_{600 \mathrm{~nm}}=0.01$, where $5 \mu \mathrm{M}$ of external PQS signaling molecule (synthesized as previously described [15]) was added to $\Delta r p o N / p_{p q s} A-g f p$ cell suspension. $200 \mu \mathrm{L}$ of cell suspensions of each strain were loaded into wells of a 96-well microtiter plate. Six replicates of each strain were applied. Optical density at $600 \mathrm{~nm}$ and green fluorescence (excitation at $485 \mathrm{~nm}$, emission at $535 \mathrm{~nm}$ ) of these cultures were monitored over $24 \mathrm{~h}$ using a Magellen Tecan ${ }^{\circledR}$ Infinite 200 PRO plate reader.

\subsection{Caenorhabditis elegans Killing Assay}

P. aeruginosa strains were spread as a lawn and incubated on PGS agar in 6-well plate (Nunc) at $37^{\circ} \mathrm{C}$ overnight. Triplicate plates were each seeded with 20 L3-stage hermaphrodite $C$. elegans strain N2 (Bristol) [21]. Plates were incubated at $25^{\circ} \mathrm{C}$ for $24 \mathrm{~h}$, for the animals to feed on the bacterial lawn. Dead and live animals were enumerated and the \% dead over total animals was tabulated.

Supplementary Materials: Supplementary materials can be found at http://www.mdpi.com/1422-0067/ 16/12/26103/s1.

Acknowledgments: This research is supported by the National Research Foundation and Ministry of Education Singapore under its Research Centre of Excellence Programme, the Start-up Grant (M4330002.C70) from Nanyang Technological University and AcRF Tier 2 (MOE2014-T2-2-172) from Ministry of Education, Singapore. Ke Wang was supported by the National Natural Sciences Foundation of China $(81,460,003)$. We thank Mingjun Yuan from Nanyang Technological University for his help with the HPLC analysis.

Author Contributions: Michael Givskov, Ke Wang and Liang Yang defined the research theme. Zhao Cai, Yicai Chen, Song Lin Chua and Yang Liu designed methods and experiments, carried out the laboratory experiments, analyzed the data, interpreted the results and wrote the paper. Joey Kuok Hoong Yam and $\mathrm{Su}$ Chuen Chew co-designed biofilm experiments, discussed analyses, interpretation, and presentation. All authors have contributed to, seen and approved the manuscript.

Conflicts of Interest: The authors declare no conflict of interest. 


\section{References}

1. Lieberman, T.D.; Flett, K.B.; Yelin, I.; Martin, T.R.; McAdam, A.J.; Priebe, G.P.; Kishony, R. Genetic variation of a bacterial pathogen within individuals with cystic fibrosis provides a record of selective pressures. Nat. Genet. 2014, 46, 82-87. [CrossRef] [PubMed]

2. Feliziani, S.; Marvig, R.L.; Lujan, A.M.; Moyano, A.J.; di Rienzo, J.A.; Krogh Johansen, H.; Molin, S.; Smania, A.M. Coexistence and within-host evolution of diversified lineages of hypermutable Pseudomonas aeruginosa in long-term cystic fibrosis infections. PLoS Genet. 2014, 10, e1004651. [CrossRef] [PubMed]

3. Mwangi, M.M.; Wu, S.W.; Zhou, Y.; Sieradzki, K.; de Lencastre, H.; Richardson, P.; Bruce, D.; Rubin, E.; Myers, E.; Siggia, E.D.; et al. Tracking the in vivo evolution of multidrug resistance in Staphylococcus aureus by whole-genome sequencing. Proc. Natl. Acad. Sci. USA 2007, 104, 9451-9456. [CrossRef] [PubMed]

4. Yang, L.; Jelsbak, L.; Marvig, R.L.; Damkiaer, S.; Workman, C.T.; Rau, M.H.; Hansen, S.K.; Folkesson, A.; Johansen, H.K.; Ciofu, O.; et al. Evolutionary dynamics of bacteria in a human host environment. Proc. Natl. Acad. Sci. USA 2011, 108, 7481-7486. [CrossRef] [PubMed]

5. Smith, E.E.; Buckley, D.G.; Wu, Z.; Saenphimmachak, C.; Hoffman, L.R.; D'Argenio, D.A.; Miller, S.I.; Ramsey, B.W.; Speert, D.P.; Moskowitz, S.M.; et al. Genetic adaptation by Pseudomonas aeruginosa to the airways of cystic fibrosis patients. Proc. Natl. Acad. Sci. USA 2006, 103, 8487-8492. [CrossRef] [PubMed]

6. Latifi, A.; Winson, M.K.; Foglino, M.; Bycroft, B.W.; Stewart, G.S.; Lazdunski, A.; Williams, P. Multiple homologues of LuxR and LuxI control expression of virulence determinants and secondary metabolites through quorum sensing in Pseudomonas aeruginosa PAO1. Mol. Microbiol. 1995, 17, 333-343. [CrossRef] [PubMed]

7. Pearson, J.P.; Pesci, E.C.; Iglewski, B.H. Roles of Pseudomonas aeruginosa las and rhl quorum-sensing systems in control of elastase and rhamnolipid biosynthesis genes. J. Bacteriol. 1997, 179, 5756-5767. [PubMed]

8. Boucher, J.C.; Yu, H.; Mudd, M.H.; Deretic, V. Mucoid Pseudomonas aeruginosa in cystic fibrosis: Characterization of muc mutations in clinical isolates and analysis of clearance in a mouse model of respiratory infection. Infect. Immun. 1997, 65, 3838-3846. [PubMed]

9. Cabral, D.A.; Loh, B.A.; Speert, D.P. Mucoid Pseudomonas aeruginosa resists nonopsonic phagocytosis by human neutrophils and macrophages. Pediatr. Res. 1987, 22, 429-431. [CrossRef] [PubMed]

10. Totten, P.A.; Lara, J.C.; Lory, S. The rpoN gene product of Pseudomonas aeruginosa is required for expression of diverse genes, including the flagellin gene. J. Bacteriol. 1990, 172, 389-396. [PubMed]

11. Lovewell, R.R.; Collins, R.M.; Acker, J.L.; O'Toole, G.A.; Wargo, M.J.; Berwin, B. Step-wise loss of bacterial flagellar torsion confers progressive phagocytic evasion. PLoS Pathog. 2011, 7, e1002253. [CrossRef] [PubMed]

12. Mahenthiralingam, E.; Campbell, M.E.; Speert, D.P. Nonmotility and phagocytic resistance of Pseudomonas aeruginosa isolates from chronically colonized patients with cystic fibrosis. Infect. Immun. 1994, 62, 596-605. [PubMed]

13. Thompson, L.S.; Webb, J.S.; Rice, S.A.; Kjelleberg, S. The alternative sigma factor rpon regulates the quorum sensing gene rhli in Pseudomonas aeruginosa. FEMS Microbiol. Lett. 2003, 220, 187-195. [CrossRef]

14. Wade, D.S.; Calfee, M.W.; Rocha, E.R.; Ling, E.A.; Engstrom, E.; Coleman, J.P.; Pesci, E.C. Regulation of pseudomonas quinolone signal synthesis in Pseudomonas aeruginosa. J. Bacteriol. 2005, 187, 4372-4380. [CrossRef] [PubMed]

15. Ilangovan, A.; Fletcher, M.; Rampioni, G.; Pustelny, C.; Rumbaugh, K.; Heeb, S.; Camara, M.; Truman, A.; Chhabra, S.R.; Emsley, J.; et al. Structural basis for native agonist and synthetic inhibitor recognition by the Pseudomonas aeruginosa quorum sensing regulator PqsR (MvfR). PLoS Pathog. 2013, 9, e1003508. [CrossRef] [PubMed]

16. Yang, L.; Barken, K.B.; Skindersoe, M.E.; Christensen, A.B.; Givskov, M.; Tolker-Nielsen, T. Effects of iron on DNA release and biofilm development by Pseudomonas aeruginosa. Microbiology 2007, 153, 1318-1328. [CrossRef] [PubMed]

17. Yang, L.; Nilsson, M.; Gjermansen, M.; Givskov, M.; Tolker-Nielsen, T. Pyoverdine and pqs mediated subpopulation interactions involved in Pseudomonas aeruginosa biofilm formation. Mol. Microbiol. 2009, 74, 1380-1392. [CrossRef] [PubMed] 
18. Zhang, L.B.; Gao, Q.G.; Chen, W.Y.; Qin, H.Y.; Wang, H.Z.; Chen, Y.C.; Yang, L.; Zhang, G. Regulation of pqs quorum sensing via catabolite repression control in Pseudomonas aeruginosa. Microbiol-Sgm 2013, 159, 1931-1936. [CrossRef] [PubMed]

19. Mashburn, L.M.; Jett, A.M.; Akins, D.R.; Whiteley, M. Staphylococcus aureus serves as an iron source for Pseudomonas aeruginosa during in vivo coculture. J. Bacteriol. 2005, 187, 554-566. [CrossRef] [PubMed]

20. Qin, Z.Q.; Yang, L.; Qu, D.; Molin, S.; Tolker-Nielsen, T. Pseudomonas aeruginosa extracellular products inhibit staphylococcal growth, and disrupt established biofilms produced by Staphylococcus epidermidis. Microbiol-Sgm 2009, 155, 2148-2156. [CrossRef] [PubMed]

21. Hendrickson, E.L.; Plotnikova, J.; Mahajan-Miklos, S.; Rahme, L.G.; Ausubel, F.M. Differential roles of the Pseudomonas aeruginosa PA14 rpoN gene in pathogenicity in plants, nematodes, insects, and mice. J. Bacteriol. 2001, 183, 7126-7134. [CrossRef] [PubMed]

22. Reitzer, L. Nitrogen assimilation and global regulation in Escherichia coli. Annu. Rev. Microbiol. 2003, 57, 155-176. [CrossRef] [PubMed]

23. Wolfe, A.J.; Millikan, D.S.; Campbell, J.M.; Visick, K.L. Vibrio fischeri sigma(54) controls motility, biofilm formation, luminescence, and colonization. Appl. Environ. Microb. 2004, 70, 2520-2524. [CrossRef]

24. Yang, L.; Rau, M.H.; Yang, L.; Hoiby, N.; Molin, S.; Jelsbak, L. Bacterial adaptation during chronic infection revealed by independent component analysis of transcriptomic data. BMC Microbiol. 2011, 11, 184. [CrossRef] [PubMed]

25. Lore, N.I.; Cigana, C.; de Fino, I.; Riva, C.; Juhas, M.; Schwager, S.; Eberl, L.; Bragonzi, A. Cystic fibrosis-niche adaptation of Pseudomonas aeruginosa reduces virulence in multiple infection hosts. PLoS ONE 2012, 7, e35648. [CrossRef] [PubMed]

26. Schulz, S.; Eckweiler, D.; Bielecka, A.; Nicolai, T.; Franke, R.; Dotsch, A.; Hornischer, K.; Bruchmann, S.; Duvel, J.; Haussler, S. Elucidation of sigma factor-associated networks in Pseudomonas aeruginosa reveals a modular architecture with limited and function-specific crosstalk. PLoS Pathog. 2015, 11, e1004744. [PubMed]

27. Sonnleitner, E.; Gonzalez, N.; Sorger-Domenigg, T.; Heeb, S.; Richter, A.S.; Backofen, R.; Williams, P.; Huttenhofer, A.; Haas, D.; Blasi, U. The small RNA PhrS stimulates synthesis of the Pseudomonas aeruginosa quinolone signal. Mol. Microbiol. 2011, 80, 868-885. [CrossRef] [PubMed]

28. Sonnleitner, E.; Schuster, M.; Sorger-Domenigg, T.; Greenberg, E.P.; Blasi, U. Hfq-dependent alterations of the transcriptome profile and effects on quorum sensing in Pseudomonas aeruginosa. Mol. Microbiol. 2006, 59, 1542-1558. [CrossRef] [PubMed]

29. Toledo-Arana, A.; Merino, N.; Vergara-Irigaray, M.; Debarbouille, M.; Penades, J.R.; Lasa, I. Staphylococcus aureus develops an alternative, ica-independent biofilm in the absence of the arlRS two-component system. J. Bacteriol. 2005, 187, 5318-5329. [CrossRef] [PubMed]

30. Heeb, S.; Itoh, Y.; Nishijyo, T.; Schnider, U.; Keel, C.; Wade, J.; Walsh, U.; O'Gara, F.; Haas, D. Small, stable shuttle vectors based on the minimal pVS1 replicon for use in gram-negative, plant-associated bacteria. Mol. Plant Microbe Interact. 2000, 13, 232-237. [CrossRef] [PubMed]

31. Bertani, G. Studies on lysogenesis. I. The mode of phage liberation by lysogenic Escherichia coli. J. Bacteriol. 1951, 62, 293-300. [PubMed]

32. Clark, D.J.; Maaløe, O. DNA replication and the division cycle in Escherichia coli. J. Mol. Biol. 1967, 23, 99-112. [CrossRef]

33. Fletcher, M.P.; Diggle, S.P.; Camara, M.; Williams, P. Biosensor-based assays for PQS, HHQ and related 2-alkyl-4-quinolone quorum sensing signal molecules. Nat. Protoc. 2007, 2, 1254-1262. [CrossRef] [PubMed]

34. Chew, S.C.; Kundukad, B.; Seviour, T.; van der Maarel, J.R.; Yang, L.; Rice, S.A.; Doyle, P.; Kjelleberg, S. Dynamic remodeling of microbial biofilms by functionally distinct exopolysaccharides. MBio 2014, 5, e01536-e01514. [CrossRef] [PubMed]

(C) 2015 by the authors; licensee MDPI, Basel, Switzerland. This article is an open access article distributed under the terms and conditions of the Creative Commons by Attribution (CC-BY) license (http://creativecommons.org/licenses/by/4.0/). 